\author{
А.Д. Попова, В.А. Семаль, \\ О.В. Нестерова, А.В. Брикманс
}

\title{
ИЗМЕНЕНИЕ ФИЗИЧЕСКИХ СВОЙСТВ ПОЧВ ПРИ ПРИМЕНЕНИИ БИОЧАРА КАК ПРИМЕРА НИЗКОУГЛЕРОДНЫХ ТЕХНОЛОГИЙ В СЕЛЬСКОМ ХОЗЯЙСТВЕ*
}

За последние 10 лет в мире получено довольно немалое количество положительных результатов от внедрения биоугля в практику сельского хозяйства зарубежных стран (Рижия, 2014). Помимо потенциала для открытия новых прибыльных рынков в области сельского хозяйства и промышленности, биоуголь имеет немалую перспективу в защите почв и климате планеты (Разумов, 2015), что является важным для всего мирового сообщества. Однако чтобы решить проблему рационального применения биоугля в сельском хозяйстве, требуется больше данных и дополнительных исследований.

Одним из важных моментов в повышении плодородия агропочв являются водно-физические показатели. В условиях интенсивного земледелия почвы испытывают на себе сильную антропогенную нагрузку, подвергаются воздействию различных приемов возделывания культур, предусматривающих многократные проходы техники, больших норм удобрений и средств химизации, что может привести как к негативному влиянию на почву, так и на почвенные процессы (Козыбаева, 2017). В муссонном климате Приморского края тяжелый гранулометрический состав, плохие водно-воздушные свойства (Ивлев и др., 2001) в совокупности с влиянием механического воздействия на почвы приводит к ухудшению условий роста и развития растений, а это, в свою очередь, может снизить урожай сельскохозяйственных культур.

Целью исследования являлось выяснение влияния внесения разных доз биоугля на изменения физических и гидрофизических характеристик агротёмногумусовых подбелов на участках с наличием или отсутствием внутрипочвенного дренажа.

\footnotetext{
* Исследование выполнено при финансовой поддержке РФФИ (№ 19-29-05166).
} 
Были поставлены следующие задачи:

1. По литературным источникам найти информацию о влиянии биоугля на физические свойства почв.

2.Определить данные показателей физических свойств (гранулометрический состав, объёмная масса, общая порозность) агротёмногумусовых подбелов.

3. Определить данные по гидрофизическим показателям (естественная влажность, полная влагоёмкость, наименьшая влагоёмкость, влажность разрыва капилляров, диапазон продуктивной влаги) агротёмногумусовых подбелов.

Огромный интерес к биоуглю, проявляемый в последние годы во многих странах вызван тем, что его использование является одним из возможных способов решения продовольственных и некоторых экологических проблем. Биоуголь благодаря своим свойствам может применяться для повышения характеристик бедных гумусом и питательными веществами почв, что в итоге может повлиять на повышение урожайности сельскохозяйственных культур (Соколик, 2015).

Внесение биоугля в почву может изменить физические свойства почвы, такие как текстура, структура, распределение размеров пор и плотность, водоудерживающая способность, рост растений и обрабатываемость почвы (Downie, 2009).

Verheijen (2009) утверждает, что механизмы, которые приводят к потенциальным улучшениям удержания воды, обеспечиваемым биоуглем, относительно просты. Добавление биоугля в почву может оказывать прямое и косвенное воздействие на сохранение почвенной влаги, которое может быть коротким или долговременным. Удержание влаги в почве определяется распределением и связностью пор в почвенной среде, которая в значительной степени регулируется размером частиц (текстурой) в сочетании со структурными характеристиками (агрегацией) и содержанием органического вещества.

Полевые опыты были заложены в прибрежной агроклиматической зоне Приморского края на опытном поле Приморской ООС - филиале ФГБНУ ФНЦО (с. Суражевка Артемовского городского округа Приморского края). Почва опытных участков - агротемногумусовый подбел (По- 
левой определитель почв России, 2008) тяжелого гранулометрического состава с высокими агрохимическими показателями.

Эксперимент с биоуглём был заложен в июне 2018 г, в июле и в августе были отобраны образцы в 5-кратных повторностях. На опытных участках в сочетании с дозами биоугля вносились и минеральные (аммиачная селитра с содержанием азота $34 \%$; аммофос с содержанием фосфора $50 \%$ и азота 10\%; хлористый калий с содержанием калия $60 \%$ ), На экспериментальной площадке вносили биоуголь компании «Красилов и К», произведенный из древесных остатков березы Betula alba методом пиролиза при температуре $360-380{ }^{\circ} \mathrm{C}$.

В 2017 г. проводились исследования на том же опытном участке, где исследовалось влияние только органических, минеральных и сочетание органо-минеральных удобрений, было заложено 2 разреза. В 2019 г., через 6 месяцев после последнего отбора образцов, были отобраны новые образцы для исследования, заложены 1 полуяма и 1 прикопка.

Е.И. Шеин (2009) отмечает, что гранулометрический состав почв является важной генетической и агрономической характеристикой, от него зависят почти все физические свойства почв: порозность, влагоемкость, водопроницаемость, водоподъемная способность, воздушный и тепловой, режимы. Наличие глинистых частиц в почвах и грунтах придает им пластичность, имеющую большое значение при обработке почв (Вадюнина, 1986).

По результатам гранулометрического анализа агротёмногумусовых подбелов за 2017 и 2019 гг. на участке без внутрипочвенного дренажа максимум содержания крупной пыли $(0,05-0,01)$ приходится на пахотные горизонты. В иллювиальных горизонтах в 2017 г. практически одинаковое содержание фракций крупной пыли и ила, в 2019 г. фракция ила занимает большую часть - 42 \% и минимум фракции, происходит увеличение количества ила вниз по профилю. Иллювиальный горизонт ВТ1 имеет одинаковое содержание фракции ила - 39 \% и минимум приходится на фракции крупного и среднего песка. По классификации Качинского поверхностные горизонты относятся к глинам легким, элювиальные горизонты EL - к суглинкам тяжелым и глинам средним, иллювиальные горизонты ВТ1 - к глинам средним.

В 2017 и 2019 гг. в агротёмногумусовых подбелах на участке с внутрипочвенным дренажом определилось большее содержание в пахотных 
горизонтах фракции крупной пыли (30 и 29 \% соответственно), минимум фракции крупного и среднего песка и одинаковое содержание в 2019 г. фракции песка мелкого, вниз по профилю также происходит увеличение количества ила (лессиваж), в иллювиальных горизонтах отмечено наибольшее содержание этой фракции - 42 и 35 \%. Поверхностный горизонт в 2017 г. - суглинок тяжелый, в 2019 г. - глина легкая, переходящая в глину среднюю, элювиальные горизонты - глина легкая и глина средняя.

В поверхностных горизонтах в 2018 и 2019 гг. в агротёмногумусовых подбелах на участке без внутрипочвенного дренажа с добавлением биоугля происходят некоторые изменения в содержании фракций. Так, наибольшее содержание приходится на фракцию крупной пыли во всех вариантах. В 2018 г. с повышением дозы биоугля происходит небольшое увеличение фракции ила и пыли мелкой, самое меньшее количество приходится на песок крупный и мелкий, но там происходит аналогичная зависимость. В 2019 г. отмечено уменьшение фракций ила с увеличением дозы биоугля. Самое малое значение фракций приходится на песок крупный и мелкий и с увеличением дозы биоугля происходит некоторое увеличение этой фракции, что особенно заметно в варианте опыта 2019 года, почвы - глины легкие.

В поверхностных горизонтах 2018 и 2019 гг. в агротёмногумусовых подбелах на участке с внутрипочвенным дренажом с добавлением биоугля замечена та же тенденция, что и в варианте опыта с отсутствием дренажной системы, максимум приходится на фракции крупной пыли $28-35$ \%. В варианте опыта 2018 г. происходит увеличение фракции ила, а в 2019 г. уменьшение фракции. Наименьшая доля - фракция песка крупного и мелкого, здесь особых различий не наблюдается, почвы - суглинок тяжелый, глины легкие и средние. Пахотные горизонты по гранулометрическому составу являются тяжелыми, вниз по профилю идёт увеличение илистой фракции, что характерно для темногумусовых подбелов, сформированных на делювии глинистых сланцев.

Объёмная масса и порозность почв имеют важное значение в оценке почвенного плодородия. Плотность почвы во многом определяет урожай растений, она оказывает влияние на рост корней растений, так как уплотненная почва является существенной преградой для их проникновения. При проходе тяжелой техники, когда повышена влажность, поверхностный горизонт может стать сильно уплотненным. Как правило, разрыхлить поверхностный пахотный слой почвы не составляет проблемы, достаточно 
его вспахать, взрыхлить различными почвообрабатывающими орудиями. Но вот разрыхлить агрегаты - основное хранилище питательных веществ, воды, почвенной биоты, значительно сложнее (Шеин, 2005). Восстановление внутриагрегатной порозности обязано деятельности почвенных микроорганизмов, накоплению специфических органических веществ. Необходимо применение органических и зеленых удобрений, влияющих на жизнедеятельность почвенных микроорганизмов, улучшающих состояние почвы, как раз в решении этой проблемы может помочь внесение биоуголя.

По данным результатов в варианте опыта без дренажа (контроль) за

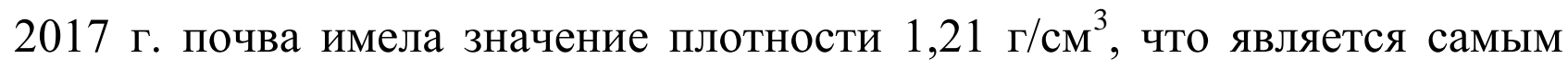
высоким показателем из всех вариантов, в 2018 году значения плотности значительно понизились, что возможно из-за обработки техникой, в вариантах с биоуглём значения плотности снижаются до 0,97 г/см ${ }^{3}$. Через год после применения биоугля (в 2019 г.) значения плотности выросли незначительно (до $1,17 \Gamma / \mathrm{cm}^{3}$ ) в варианте с биоуглём в дозе $1 \mathrm{\kappa г} / \mathrm{m}^{2}$, в то время как в дозе с 3 кг $/ \mathrm{M}^{2}$ значения плотности ниже. Это можно объяснить тем, что биоуголь, распадаясь на более мелкие отдельности, частично блокирует поры, тем самым увеличивая плотность почвы. Но, в общем, это не повлияло отрицательно на почву, по оценке Качинского - это типичная величина для пахотного горизонта культурной пашни (Ознобихин, 1985).

В вариантах опыта с дренажной системой контроль значения объёмной массы в 2017 г. незначительно выше по сравнению с 2018 и 2019 гг. В 2018 г. значения не претерпевают заметных изменений, лишь с биоуг-

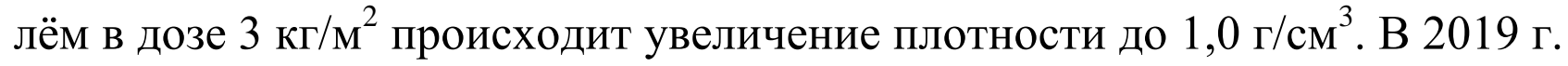
эти значения находятся также на этом уровне.

Общая порозность (скважность или пористость) почвы показывает суммарный объем пустот, различных по величине и форме. Скважность зависит от гранулометрического, агрегатного состава и структуры почвы, формы частиц, плотности их упаковки, пронизанности почвы корнями. Величина общей порозности почвы определяет в основном водный и воздушный режим почвы, полную влагоемкость и воздухоемкость; от нее зависит передвижение воды в почве: водопроницаемость, глубина промачивания, подъем грунтовых вод, испарение.

В вариантах опыта 2017 г. без дренажа (контроль) значение порозности почв 50,1 \%, что является неудовлетворительным по шкале Качинского (Шеин, 2005), значения в варианте с биоуглём 3 кг/м² в 2018 и 2019 гг. зна- 
чительно увеличились и получили оценку «отличная». По сравнению с вариантом опыта с биоуголем в 1 кг/м² 2018 г. в 2019 г. произошло ухудшение.

В варианте опыта с дренажем (контроль) 2017 г. заметна та же тенденция, что и в варианте без дренажа. С добавлением биоугля значения порозности высокие и держатся примерно на одном уровне, оценка - отличная. Через год после внесения значения порозности уменьшились до $59,7 \%$, оценка - отличная. За год порозность почв уменьшилась, но это сильно не повлияло на значения оценки.

Естественная влажность (ЕВ) - минимальное количество воды, которое почва может удерживать в воздушно-сухом состоянии.

Влажность, определенная с помощью влагомера "SM150 soil Moisture Sensor" (точность определения \pm 3 \%) в полевых условиях и естественная влажность, рассчитанная в лаборатории, значительно коррелирует с осадками.

За 2018 год количество влаги выше по сравнению с 2019 годом, за июль и август выпало достаточное большое количество осадков - 113,3 и 256,6 мм (по данным агрометеостанции «Садгород»). В мае 2019 года выпавшее количество осадков меньше, что и прослеживается результатах.

В основном способность биоугля увеличивать влажность почв связана с его физико-химическими характеристиками, в частности пористостью и удельной поверхностью, а также высокой способностью к сорбции и перераспределением почвенных пор. В случае на тяжелых почвах с биоуглём в большем количестве есть тенденция к уменьшению значения влажности.

Полная влагоемкость (ПВ) - наибольшее количество влаги, которое может содержаться в почве при условии заполнения ею всех пор, за исключением пор с защемленным воздухом, которые составляют, как правило, не более $5-8 \%$ от общей порозности. Следовательно, ПВ почвы численно близка к порозности (скважности) почвы, но она будет значительно ниже (Шеин, 2005).

При влажности, равной ПВ, в почве содержатся максимально возможные количества всех видов воды: связанной (прочно- и рыхло-) и свободной (капиллярной и гравитационной). Можно сказать, что ПВ характеризует полную водовместимость почв. Зависит она, как и наименьшая влагоемкость, не только от гранулометрического состава, но и от структурности и порозности почв. Полная влагоемкость колеблется в пределах 40-50\%, в отдельных случаях она может возрасти до 80 или опуститься 
до 30 \%. Состояние полного насыщения водой характерно для горизонтов грунтовых вод (Клебанович, 2016).

Значения полной влагоемкости в варианте опыта бездренажной системы за 2018 год повышаются с увеличениеи дозы биоугля, за 2019 год значения практически на уровне, кроме варианта с биоуглём 1 кг/м ${ }^{2}-46$, $6 \%$. В дренажной системе за 2018 год происходит уменьшение значений с добавленим биоугля, в 2019 - небольшое увеличение.

Наименьшая влагоемкость (НВ) - наибольшее количество капиллярно-подвешенной влаги, которое может удержать почва после стекания избытка влаги при глубоком залегании грунтовых вод. Термину наименьшая влагоемкость соответствуют термины полевая влагоемкость (ПВ), общая влагоемкость (OB) и предельная полевая влагоемкость (ППВ). Последний термин особенно широко используется в агрономической практике и в мелиорации; термин «полевая влагоемкость» широко распространен в иностранной литературе, особенно американской.

Наименьшая влагоемкость зависит главным образом от гранулометрического состава почв, от их оструктуренности и плотности (сложения). В почвах глинистых НВ достигает 50 - 60 \% от веса почвы, суглинистых $30-40 \%$, супесчаных 15 - $25 \%$, песчаных - не превышает $10-15 \%$.

Наименьшая влагоемкость почв является очень важной гидрологической характеристикой почвы. С ней связано понятие о дефиците влаги в почве, по НВ рассчитываются поливные нормы. Это равновесная влажность, которую возможно определить в поле, она наблюдается в почве весной, после таяния снега, стекания гравитационной воды и представляет собой весенние запасы влаги. Именно потому, что НВ представляет количество воды, которое удерживается почвой после осадков или полива, эта величина является основой большинства гидрологических, мелиоративных расчетов.

Таким образом, наименьшая влагоемкость - важнейшая в агрофизике почвенно-гидрологическая константа. Она важна и тем, что характеризует содержание в почве воздуха в этот момент.

Наименьшая влагоёмкость в вариантах опыта бездренажной системы и с добавлением биоугля за 2018 год не претерпевает сильных различий как и в варианте опыта с дренажом. В 2019 году произошло увеличение значений по сравнению с предыдущим годом, а с биоуглём в дозе 3 кг/м значения понизились до 32,4 \% оценивается как «хорошая» (Синельников, 
2000). В дренажной системе значения за 2018 год повысились по сравнению с 2019 годом - с 33,9 до 39,4\%.

Влажность разрыва капиллярной связи (ВРК) - влажность почвы, при которой прерывается гидравлическая связь капиллярной сети и подвижность влаги в процессе иссушения резко уменьшается. Находится в интервале влажностей между наименьше влагоемкостью и влажностью устойчивого завядания растений (Шеин, 2014).

Капиллярно-подвешенная вода при испарении передвигается в жидкой форме к испаряющей поверхности в пределах всей промоченной толщи по капиллярам, сплошь заполненным водой. Но при определенном снижении влажности, характерном для каждой почвы, восходящее передвижение этой воды прекращается или резко затормаживается. Потеря способности к такому передвижению объясняется тем, что в почве при испарении исчезает сплошность заполнения капилляров водой, т. е. в ней не остается систем пор, сплошь заполненных влагой и пронизывающих промоченную часть почвенной толщи. Эту критическую величину влажности назвали влажностью разрыва капиллярной связи (ВРК).

Таким образом, влажность разрыва капилляров - это влажность, при которой подвижность капиллярной воды в процессе снижения влажности резко уменьшается. Вода, однако, остается в мельчайших порах, в углах стыка частиц (мениски стыковой влаги). Эта влага неподвижна, но физиологически доступна корешкам растений. При влажности ниже ВРК рост растений замедляется и их продуктивность снижается. В почвах и грунтах эта величина варьирует довольно сильно, составляя в среднем около 50 $60 \%$ от наименьшей влагоемкости почв в легких почвах и около $70 \%-$ в тяжелых. На содержание воды, соответствующей ВРК, помимо гранулометрического состава почв, существенное влияние оказывает их структурное состояние. В бесструктурных почвах запасы воды расходуются на испарение значительно быстрее, чем в почвах с агрономически ценной структурой, и в них влажность будет быстрее достигать ВРК (Клебанович, 2016).

В вариантах опыта без дренажа с биоуглём за 2018 - 2019 гг. происходит снижение значений (рис. 1).

Биоуголь адсорбирует влагу, таким образом, условия для растений становятся лучше, особенно с учетом муссонного климата, где периодически происходят застаивание влаги и может начаться анаэробиозис, что может привести к гниению корней. Величина ВРК зависит от механиче- 
ского состава - содержания илистой фракции и от сложения и структуры почвы. В дренажной системе происходит уменьшение значений в 2018 году, в 2019 году значения сильно не варьируют.
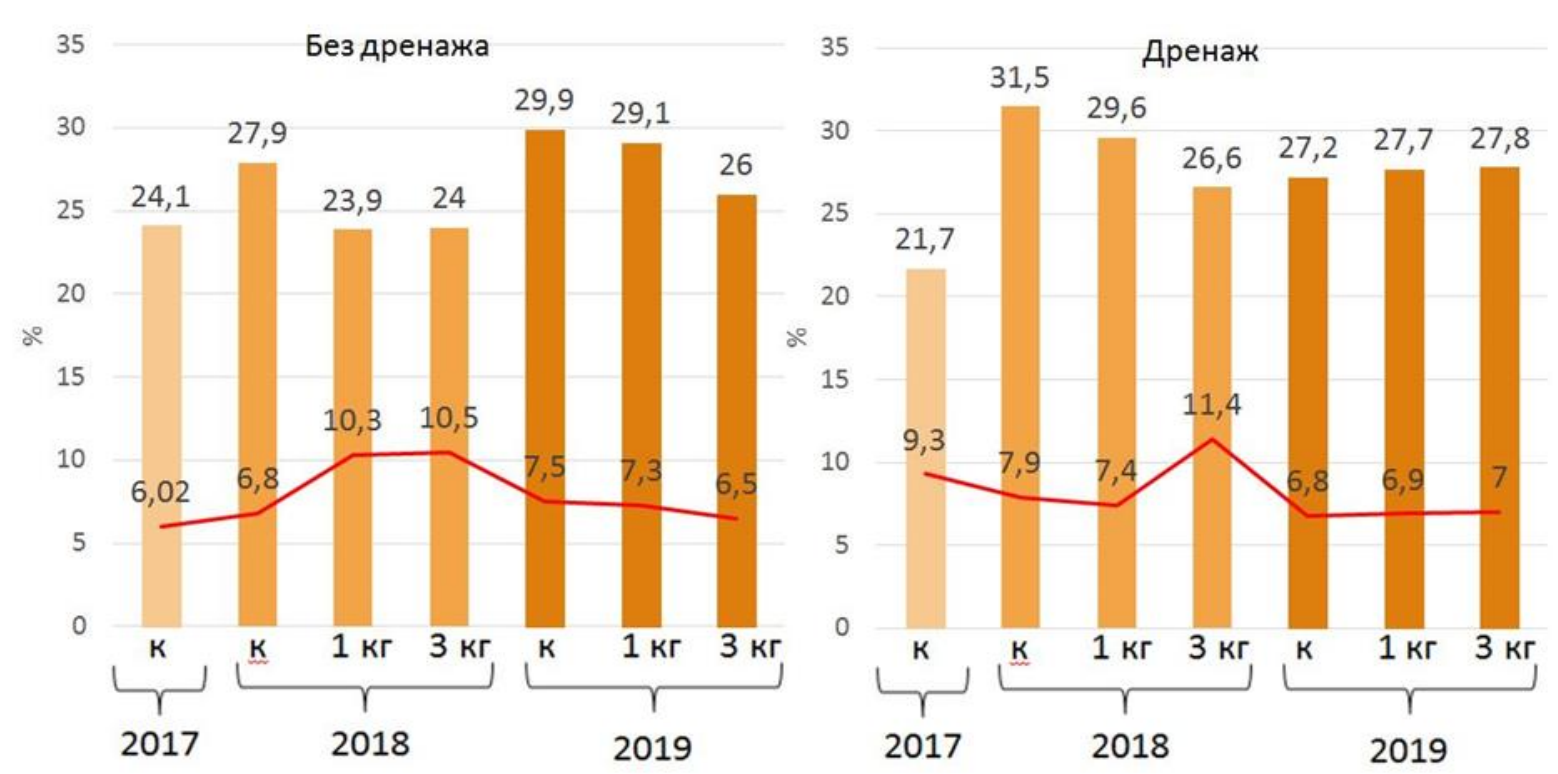

Puc. 1. Гистограмма распределения значений диапазона легковподвижной влаги и влажности разрыва капилляров на бездренажной и дренажной системе по годам

Диапазон легкоподвижной, легкодоступной для растений влаги (НВ ВРК) - рассматривается как категория между отдельными гидрологическими константами. Это наиболее эффективная часть той продуктивной влаги, которая характеризуется диапазоном (HB - В3). Иногда этот диапазон заменяют другим (НВ - 70\% НВ). Этот диапазон влажности следует поддерживать в корнеобитаемом слое, чтобы избежать непродуктивных потерь влаги на стекание ее в нижележащие слои и в то же время способствовать наиболее эффективной работе фотосинтетического аппарата растений (Шеин, 2014).

Диапазон легкоподвижной влаги имеет тенденцию к увеличению с повышением доз биоугля в бездренажной системе. За 2019 год в бездренажной системе происходит небольшое уменьшение с количеством биоугля, в дренажной незначительный рост значений (рис. 1).

Результаты гранулометрического анализа почв показали, что пахотные горизонты в варианте опыта с отсутствием дренажной системы и с добавлением доз биоугля в 2018 - 2019 годах относятся к глинам лёгким. В варианте опытов с дренажной системой есть различия, пахотный горизонт с дозой биоугля 1 кг/м² в 2018 году оказался тяжелее контроля и ва- 
рианта с биоуглём в дозе 3 кг/м², варианты 2019 года сильно не различаются - глины легкие. В агротемногумусовых подбелах во всех вариантах опыта идет утяжеление гранулометрического состава вниз по профилю.

В вариантах опытов с отсутствием дренажной системы и с увеличением доз биоугля произошло увеличение значений порозности почв, в опытах с дренажом сильных изменений не произошло как в 2018 и 2019 годах, в 2019 году порозность стала меньше во всех вариантах опыта по сравнению с предыдущим годом. В системе без дренажа через год таких изменений не наблюдается.

Естественная влажность в почвах значительно выше за 2018 год, так как был достаточно влажный период в момент отбора образцов, в месяц отбора в 2019 году было очень сухо, что и объясняет такую тенденцию. С добавлением биоугля в дозе 1 кг/м² есть некоторое увеличение значений в бездренажной системе, в дренажной с дозой биоугля 1 кг/м ${ }^{2}$ есть небольшое уменьшение значений. По сравнению с контролем особых изменений не происходит.

Значения полной влагоемкости в варианте опыта бездренажной системы за 2018 год повышаются с увеличением дозы биоугля, за 2019 год значе-

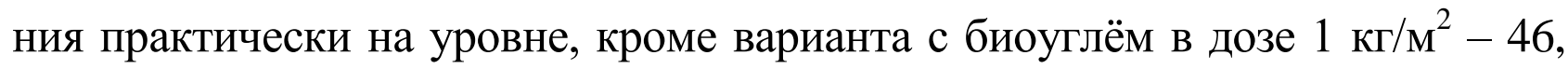
$6 \%$. В дренажной системе за 2018 год происходит уменьшение значений с добавлением биоугля, в 2019 - небольшое увеличение.

Наименьшая влагоёмкость в вариантах опыта бездренажной системы и с добавлением биоугля за 2018 не претерпевает сильных различий, как и в варианте опыта с дренажом. В 2019 году произошло увеличение значений по сравнению с предыдущим годом, а с биоуглём в дозе 3 кг/м м $^{2}$ начения понизились до 32,4\%. В дренажной системе значения за 2018 год выше значений за 2019 год.

В вариантах опыта без дренажа с биоуглём за 2018-2019 года происходит снижение значений. В дренажной системе происходит уменьшение значений в 2018 году, в 2019 году значения сильно не варьируют. Диапазон продуктивной влаги имеет тенденцию к увеличению с повышением доз биоугля в бездренажной системе. За 2019 год в бездренажной системе происходит небольшое уменьшение с количеством биоугля, в дренажной незначительный рост значений. 


\section{Литература}

1. Ивлев А.М., Дербенцева А.М., Голов В.И., Трегубова В.Г. Агрохимия почв юга Дальнего Востока: Учеб. пособие. М.: Круглый год, 2001. 104 с.

2. Козыбаева Ф.Е., Бейсеева Г.Б., Тоқтар М., Ажикина Н.Ж. Влияние биоугля на водно-физические свойства и структурное состояние предгорных темно-каштановых почв Заилийского Алатау // International scientific and practical conference world science. 2017. № 5 (21). C. 16 - 21.

3. Полевой определитель почв. М.: Почвенный институт им. В.В. Докучаева, 2008. 182 с.

4. Клебанович Н. В. Гидрофизика почв : учеб. материалы по дисциплине «Биофизика почв» для студентов спец. 1-01 0201 «География»/ Минск: БГУ, 2016. 41 с.

5. Ознобихин В.И., Синельников Э.П. Характеристика основных свойств почв и пути их рационального использования. Уссурийск: Прим. с.-Х. ин-т, 1985. 72 с.

6. Разумов Е.Ю. Биоуголь: современное представление // Вестник Казанского технологического университета. 2015. Т.18. № 2. С. 220 - 222.

7. Рижия Е.Я. Применение биоугля в сельском хозяйстве Российской Федерации: Методические рекомендации. - СПб.: АФИ, 2014. 28 с.

8. Синельников Э.П. Оптимизация свойств и режимов периодически переувлажняемых почв : монография / ДВО ДОП РАН, Приморская ГСХА. - Уссурийск, 2000. 296 с.

9. Шеин Е. В. Курс физики почв: Учебник. М.: Изд-во МГУ, 2005. 432 с.

10. Шеин Е. В. Гранулометрический состав почв: проблемы методов исследования, интерпретации результатов и классификаций // Почвоведение, 2009. № 3. С. $309-317$.

11. Шеин Е. В. Агрофизика: учеб, пособие / Е.В. Шеин и др.; Владим. Гос. ун-т им. А.Г. и Н.Г. Столетовых. - Владимир: Изд-во ВлГУ, 2014. $92 \mathrm{c}$.

12. Downie A., Crosky A., Munroe P. Physical properties of biochar // Biochar for Environmental Management: Science and Technology. - Earthscan, London, 2009. - P.13 - 32.

13. Verheijen F., Jeffery S., Bastos A.C. Biochar application to soils, a critical scientific review of effects on soil properties, processes and functions. Luxembourg: Office for the Official Publications of the European Communities, 2009. $149 \mathrm{p}$. 